\title{
IL-1B $(C+3954 T)$ Gene Polymorphism and Susceptibility to Gastric Cancer in the Iranian Population
}

\author{
Ahmad Ismaili ${ }^{1 *}$, Kheirollah Yari ${ }^{2,3}$, Mohammad-Taher Moradi ${ }^{2,3}$, Maryam \\ Sohrabi $^{2,3}$, Danial Kahrizi ${ }^{2,4}$,Elham Kazemi ${ }^{2,5}$, Zahra Souri
}

\begin{abstract}
Background: Gastric cancer as one of the most important diseases affecting health in all worldwide. Current studies have confirmed associations of cytokine gene polymorphisms with the risk of gastric cancer development. The current research aimed to assess the association of IL-1B+3954 genotypes with the risk of gastric cancer in the Iranian population. Materials and Methods: This case-control study covered 49 gastric cancer patients compared to 53 cancer free individuals as a control group. Genomic-DNA extraction was carried out from bioptic samples of patients and peripheral blood of healthy volunteers. Polymorphism of IL-1B +3954 genotypes were analysed with a polymerase chain reaction-restriction fragment length polymorphism (PCR-RFLP) method. Results: The frequencies of IL-1B +3954 A1A1, A1A2 and A2A2 genotypes in healthy individuals were 26.4, 66 and $7.6 \%$, respectively. However, in gastric cancer patients, A1A1, A1A2 and A2A2 with 4.1, 51 and $44.9 \%$ were observed $(\mathbf{p}<0.05)$. Conclusions: The findings of our results show a positive association between the IL-1B+3954 genotype distribution and the risk of gastric cancer disease in the Iranian population.
\end{abstract}

Keywords: Gastric cancer - IL-1B+3954 - gene polymorphism - Iran

Asian Pac J Cancer Prev, 16 (2), 841-844

\section{Introduction}

Gastric cancer (GC) is well-documented as one of the most common cancers that affected health in all over the world (Zare et al., 2013; Huang, 2014; Yu et al., 2014). Gastric cancer is the second common cause of mortality rate in the worldwide (Kulmambetova et al., 2014). The peak occurrence of gastric cancer is in the 70th decade, and the disease is roughly twice as common in men as in women. There is a noticeable geographic variation, with the highest rates reported in East Asia, South America and Eastern Europe and the lowest rates in the United States and Western Europe (Forman and Burley, 2006). Regions of northern and northwestern of Iran are high risk areas for gastric cancer-related death (Moradi et al., 2013). Pathogenesis and progression of gastric cancer disease depend on interactions between genetic background, lifestyle and environmental risk factors such as infectious, dietary, cigarette smoking, alcohol, pollutants, stress, obesity and physical inactivity (Anand et al., 2008). Reported studies indicate that genetic factors such as single nucleotide polymorphisms, insertion or deletion mutations and rearrangements might have a strong influence on individual's susceptibility to gastric cancer (Zeng et al., 2003; Camargo et al., 2006; Yu et al.,
2014). Helicobacter pylori infection leads to persistent colonisation and chronic inflammation of the gastric mucosa and increasing the risk of gastric malignancies ( $\mathrm{Rad}$ et al., 2004). Therefore, now it is recognized as the most common etiologic factor of infection-related cancers (Moradi et al., 2013). Cytokines as the putative mediator of immune system play an significant role in some of biological activities such as cell proliferation, tissue development, gene expression, DNA repair and inflammation processes (Ayazi et al., 2013). One of the well studied cytokines that its genotypes are correlated with gastric cancer occurrence is interleukin-1 genotype. IL-1 genes family with two distinct but functionally similar types, IL- $1 \alpha$, IL- $1 \beta$, are located in a cluster on the long arm of human chromosome 2q13 (Nicklin et al., 1994; Ayazi et al., 2013). Interleukin-1 beta (IL1B), a proinflammatory cytokine expressed by activated macrophages and numerous other types of cells, is supposed to play a critical function in the pathogenesis of some diseases (Liu et al., 2010). Epidemiological evidence confirmed that IL- $1 \beta$ is highly polymorphic, and a few of the genetic polymorphisms of this cytokine are associated with an increased risk of pathogenesis of gastric cancer. The plausibility of this association rests in the fact that several of these genetic polymorphisms

${ }^{1}$ Department of Agronomy and Plant Breeding, Faculty of Agriculture, Lorestan University, ${ }^{2}$ Medical Biology Research Center, Kermanshah University of Medical Sciences, ${ }^{3}$ Zagros Bioidea Company, Razi University Incubator, ${ }^{4}$ Department of Agronomy and Plant Breeding, Faculty of Agriculture, ${ }^{6}$ Department of Biology, Faculty of Science, Razi University, ${ }^{5}$ Social Security Organization, Kermanshah,Iran*For correspondence: ismaili.a@lu.ac.ir;ahmad_ismaili@yahoo.com 
are associated with increased production of IL-1 beta, a powerful inhibitor of gastric acid secretion, which, in turn, appears to modulate cancer risk.

However, the possible association between genotype distribution of the related candidate genes with gastric cancer in different ethnicities has been studied; According to literature, there has been no reported data for examine possible association between the polymorphism of IL-1 $\beta$ and gastric cancer among Iranian populations. Therefore, our aim of current study was to study the IL-1B ${ }^{+3954}$ gene polymorphism and its association with gastric cancer among a sample of the Iranian population for the first time.

\section{Materials and Methods}

DNA isolation kit was purchased from Gen Pajohan, Iran. Taq I as a restriction enzyme, agarose and polymerase chain reaction (PCR) materials were purchased from Fermentas. Specific primers were synthesized from Symbion, Fruebjergvej 3 (Denmark). The other chemicals with analytical grade were from Merck.

\section{Samples}

All gastric cancer patients were from the north and northwest provinces of Iran who admitted to the medical sciences clinics between May 2011 and June 2012. The gastric cancer diagnosis was according to standard clinical, radiological and histological parameters and results were analyzed by two experienced endoscopists. All procedures of recent research were accepted and approved by the ethics committee in Kermanshah University of Medical Sciences (Iran). Individuals who contributed to this study signed an informed consent in accordance with the Helsinki II declarations. All patients were informed about the aim and procedures of the research.

\section{Genomic DNA extraction}

Genomic DNA was isolated from endoscopic fresh biopsy samples. Tissue specimens were suspended in $550 \mu 1$ of DNA extraction buffer ( $2 \mathrm{mM}$ EDTA, $10 \mathrm{mM}$ Tris- $\mathrm{HCl}(\mathrm{pH} 8.0)$ and $400 \mathrm{mM} \mathrm{NaCl})$. The suspension was incubated at $20-30{ }^{\circ} \mathrm{C}$ for $20 \mathrm{~min}$, following the addition of Proteinase $\mathrm{K}$ and SDS (400 ng and $0.6 \%$, respectively). Then the solution was incubated at $55^{\circ} \mathrm{C}$ for $15 \mathrm{~h}$ and extracted with the GPP isolation kit (Gen Pajoohan, Iran). Also, the blood sample was collected using venipuncture from healthy volunteer and added into tubes containing Ethylene diamine tetra acetic acid (EDTA). DNA extraction from blood sample was performed with optimized protocol that reported with Moradi et al, 2014 (Moradi, 2014). Isolated DNA was stored at $-20{ }^{\circ} \mathrm{C}$ until use.

\section{Quantification of extracted DNA}

Isolated DNA was observed and confirmed by gel electrophoresis on $0.1 \%$ agarose containing DNA Safe Stain (Invitrogen). The concentration and purity of DNA were assessed with a Nanodrop (Thermo) with 260/280 measurement ratio and at the wave length of 260 and $280 \mathrm{~nm}$.
Analysis of IL-1 $1 B^{+3954}$ genotypes

The IL-1B ${ }^{+3954}$ polymorphism was assessed by PCR amplification and then RFLP analysis. A $3 \mu 1$ volume of extracted DNA was used as a template for PCR. A $182 \mathrm{bp}$ fragment was amplified with the following primer pair (Guzeldemir E, 2008): 5'TCAGGTGTCCTCGAAGAAATCAAA3'and 5'GCTTTTTTGCTGTGAGTCCCG3'. PCR amplifications were carried out at a total volume of 25 $\mu 1$ containing $500 \mathrm{ng}$ genomic DNA as template, $1 \mathrm{x}$ PCR reaction buffer, $\mathrm{MgCl}_{2}$ with $1.5 \mathrm{mM}, 0.2 \mathrm{mM}$ of $\mathrm{dNTP}$, $0.5 \mu \mathrm{M}$ of forward and reverse primers and 2 units of Taq DNA polymerase (Fermentase, USA).

Thermocycler parameters comprised of first denaturation step at $95^{\circ} \mathrm{C}$ for $7 \mathrm{~min}, 35$ cycles of denaturation at $95^{\circ} \mathrm{C}$ for $45 \mathrm{~s}$, annealing at $56^{\circ} \mathrm{C}$ for $45 \mathrm{~s}$, extension at $72^{\circ} \mathrm{C}$ for $45 \mathrm{~s}$, and then a final extension at $72^{\circ} \mathrm{C}$ for $5 \mathrm{~min}$. After amplification, $12 \mu \mathrm{l}$ of PCR products were subjected to overnight digestion with 10 units of Taq I (New England Biolabs, Beverly, MA, USA) for MnSOD at $60^{\circ} \mathrm{C}$. The PCR-RFLP was carried out using $2 \mathrm{U}$ of Taq I at $65 \mathrm{oC}$ for $15 \mathrm{~h}$. The homozygous genotype (CC) produces two fragments of $97 \mathrm{bp}$ and $85 \mathrm{bp}$ lengths, the homozygous genotype (TT) produces a fragment with $182 \mathrm{bp}$, while the heterozygous genotype (CT) produces three fragments of $182 \mathrm{bp}, 97 \mathrm{bp}$ and $85 \mathrm{bp}$ lengths that were diagnosed on $2 \%$ gel agarose.

\section{Statistics}

The significance of the difference of alleles and genotype frequencies between the groups was tested using the chi-square method. Data on quantitative characteristics are expressed as means \pm standard deviations. Odds ratios (OR) were calculated as estimates of relative risk for disease and $95 \%$ confidence intervals were measured by logistic regression using SPSS software. A two-tailed Student's t test analysis was used to compare quantitative data. Statistical significance was assumed at the $\mathrm{p}<0.05$ level. All of the statistical analyses were performed using SPSS statistical software package version 16.0.

\section{Results}

Forty nine gastric cancer patients and 53 healthy individuals as control group participated in this study. The control group, $59 \%$ men and $41 \%$ women with the mean age of $61.2 \pm 7.4$ years, were free from cancer signs. Further, the gastric cancer group consisted of $35 \%$ women and $65 \%$ men with the mean age of $64.8 \pm$ 9.1 years. There was no significant difference showed between patients and controls in terms of age and sex. In all participants, genomic DNA was extracted by DNA extraction kit as previously mentioned, and extracted DNA was evaluated by spectrophotometric assay and agarose gel electrophoresis (result not shown). To investigate the gene polymorphism, PCR-RFLP was carried out. Figure 1 shows the $2 \%$ agarose gel electrophoresis pattern of PCR products of IL-1B with a $182 \mathrm{bp}$ fragment length. After gene amplification for its verification, gel electrophoresis of the digested PCR product with Taq I as restriction enzyme was done. 
Table 1. Distribution of IL-1 $\beta$ Genotypes in Gastric Cancer and Control Group of Iranian Population

\begin{tabular}{lccrc}
\hline IL1 $\beta$ & \multicolumn{2}{c}{ Gastric Cancer } & \multicolumn{2}{c}{ Control } \\
& $\mathrm{N}$ & $\%$ & $\mathrm{~N}$ & $\%$ \\
\hline A1A1 & 2 & 4.1 & 14 & 24.6 \\
A2A2 & 22 & 44.9 & 4 & 7.6 \\
A1A2 & 25 & 51 & 35 & 66 \\
Total & 49 & 100 & 53 & 100 \\
\hline
\end{tabular}

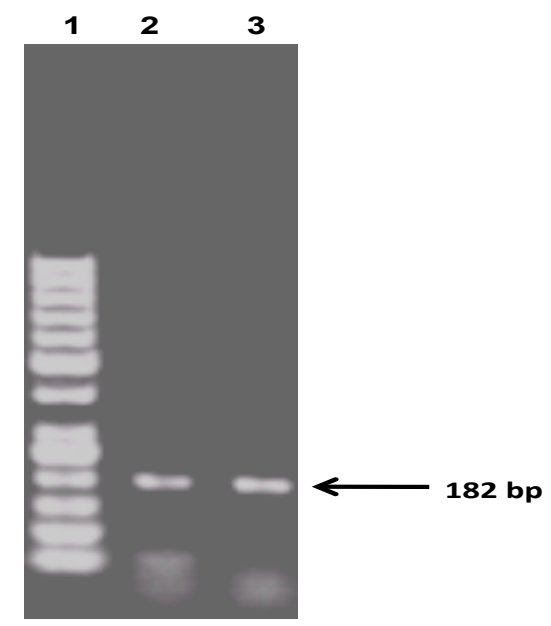

Figure 1. Agarose gel (2\%) Electrophoresis for Amplified IL-1及 Gene by PCR and Digested Product by Taq I Restriction Enzyme; from Left to Right, Lane 1 Shows 50 bp DNA Molecular Markers, Lane 2 and 3 Show a 182 bp for PCR Product Band

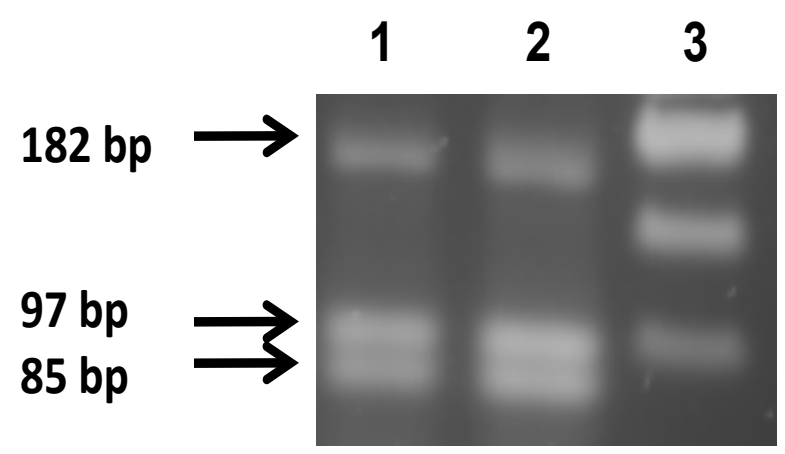

Figure 2.Agarose gel (3\%) electrophoresis for digested product by Taq I restriction enzyme; from left to right, lane 1 and 2 show Heterozygous genotypes of IL-1 $\beta$, lane 3 shows 100 bp DNA molecular markers

Distribution of IL-1B genotypes in gastric cancer patients and controls is showed in Table 1. The frequencies of IL-1B ${ }^{+3954}$ A1A1, A1A2 and A2A2 genotypes in healthy individuals were $26.4,66$ and $7.6 \%$, respectively. However, in gastric cancer patients, A1A1, A1A2 and A2A2 with 4.1,51 and 44.9\%, respectively, were observed $(\mathrm{p}<0.05)$. The frequencies of $\mathrm{IL}_{-1 \mathrm{~B}^{+3954}}$ genotypes were in Hardy-Weinberg equilibrium in both patients and controls. Agarose gel electrophoresis pattern of RFLP products of the IL-1B gene with heterozygous genotype is demonstrated in Figure 2. The findings of our results showed a positive association between IL-1B B $^{+3954}$ genotypes distribution and the risk of gastric cancer disease in Iranian population.

\section{Discussion}

Gastric cancer is the most frequent malignancy diagnosed in worldwide and it is the most common deadly cancer in Iran. The current research in a homogenous population of gastric cancer patients from north and northwest of Iran reports a significant association between IL-1B genotypes with the risk of gastric cancer. Epidemiologic studies have reported that process of gastric cancer is the result of several significant players in different stages such as environmental factors, genetic susceptibility factors and adverse living conditions, dietary habits and the prevalence of Helicobacter pylori (H. pylori) infection (Moges et al., 2006; Chiurillo, 2014). Infection with Helicobacter pylori causes a wide range of gastric pathologies to gastric malignancies (Zeng et al., 2003). Gene polymorphisms related to inflammation process such as cytokines are supposed influence the first stage of the precancerous stage (Chiurillo, 2014). The first cytokine polymorphism associated to the development of gastric cancer was reported by El-Omar et al. in 2001. This polymorphism involved of $\mathrm{C}-\mathrm{T}$ and $\mathrm{T}-\mathrm{C}$ transitions at positions -511 and -31 of the IL-1B gene, respectively, as well as the presence of a penta-allelic tandem repeat in intron 2 of the IL-1 receptor antagonist gene (IL1RN) (El-Omar et al., 2000). Recently, IL-1B gene that induced by H.pylori infection has been proposed as a key marker in determining the risk of gastric cancer. Gene regulation in IL-1 gene family, with such high frequencies of polymorphisms in expression either of its subtypes, would result in different levels of susceptibility to the disease between individuals (Li et al., 2004; Ayazi et al., 2013). Based on documents in literature, IL-1 $\alpha$ and $1 \beta$ as two very considerable proinflammatory cytokines, are considered most functional to investigate of the association between IL-1 gene polymorphism with several disease (Parkhill et al., 2000). The first study on association between IL-1 gene cluster polymorphism with gastric cancer was reported by El-Omar et al (2000) who reported a positive association between severity of gastric cancer with composite genotypes of IL-1 $\beta$ (El-Omar et al., 2000). This polymorphism leads to expression of IL-1B at high level, acid reduction, H. pylori colonization that are considered as well as risk factor for gastric cancer. Zeng et al (2003) reported that IL-1B polymorphism did not any correlation with gastric cancer in Chinese population, which echoes the finding of El-Omar et al (Zeng et al., 2003). Our results is in accordance with the results of Wen et al., (2014) that who reported the IL-1B ${ }^{+3954} \mathrm{CT}$ or the TT variant genotype was statistically significantly associated with a risk of gastric cancer in Western Chinese population (Wen et al., 2014). In fact, this genetic polymorphism is associated with increased expression of IL-1 beta as a powerful inhibitor of gastric acid secretion, which, in turn, appears to modulate cancer (Jatoi et al., 2007b).

In conclusion, our results of this research showed that there was a significant positive association between the distribution of the IL-1B gene polymorphism and gastric cancer disease. In addition, the results show that the polymorphism of this SNP is an important risk factor that is associated with gastric cancer in sample of Iranian 


\section{Ahmad Ismaili et al}

population. However, further researches with a larger sample size are required to confirm these findings. The present study that reported here is the first published research on the correlation between the IL-1B genotypes and the susceptibility to gastric cancer disease in the Iranian population. This study can be used as a basis for studying polymorphisms of other important genes in correlation to gastric cancer.

\section{Acknowledgements}

The authors are grateful for the financial support of the Lorestan University Research Council. Thanks to Zagros Bioidea Co., Razi University Incubator for all supports.

\section{References}

Anand P, Kunnumakara AB, Sundaram C, et al (2008). Cancer is a preventable disease that requires major lifestyle changes. Pharmaceutical Res, 25, 2097-116.

Ayazi G, Pirayesh M, Yari K (2013). Analysis of interleukin1 beta gene polymorphism and its association with generalized aggressive periodontitis disease. DNA Cell Biol, 32, 409-13.

Camargo MC, Mera R, Correa P, et al (2006). Interleukin-1 $\beta$ and interleukin-1 receptor antagonist gene polymorphisms and gastric cancer: a meta-analysis. Cancer Epidemiol Biomarkers Prev, 15, 1674-87.

Chiurillo MA (2014). Role of gene polymorphisms in gastric cancer and its precursor lesions: current knowledge and perspectives in Latin American countries. World $J$ Gastroenterol, 20, 4503-15.

El-Omar EM, Carrington M, Chow WH, et al (2000). Interleukin-1 polymorphisms associated with increased risk of gastric cancer. Nature, 404, 398-402.

Forman D, Burley V (2006). Gastric cancer: global pattern of the disease and an overview of environmental risk factors. Best Practice Res Clin Gastroenterol, 20, 633-49.

Guzeldemir E GM, Ozcelik O, Tastan H (2008). Interleukin-1 and tumor necrosis factor-alpha gene polymorphisms in Turkish patients with localized aggressive periodontitis. $J$ Oral Sci, 50, 151-9.

Huang C-J (2014). Factors predicting survival of patients with gastric cancer. Asian Pac J Cancer Prev, 15, 5835-8.

Jatoi A, Nguyen PL, Foster N, et al (2007). Interleukin-1 genetic polymorphisms and their relationship to the cancer anorexia/weight loss syndrome in metastatic gastric and gastroesophageal junction adenocarcinoma. J Support Oncol, 5, 41-6.

Kulmambetova GN, Imanbekova MK, Logvinenko AA, et al (2014). Association of cytokine gene polymorphisms with gastritis in a Kazakh population. Asian Pac J Cancer Prev, 15, 7763 .

Li QY, Zhao HS, Meng HX, et al (2004). Association analysis between interleukin-1 family polymorphisms and generalized aggressive periodontitis in a Chinese population. J periodontol, $\mathbf{7 5}, 1627-35$.

Liu Y-H, Chen R-H, Wu H-H, et al (2010). Association of Interleukin-1 beta (IL1B) polymorphisms with Grave's Ophthalmopathy in Taiwan Chinese patients. Investigative ophthalmology and visual science, iovs. 09-4965.

Moges F, Kassu A, Mengistu G, et al (2006). Seroprevalence of Helicobacter pylori in dyspeptic patients and its relationship with HIV infection, $\mathrm{ABO}$ blood groups and life style in a university hospital, Northwest Ethiopia. World $J$
Gastroenterol, 12, 1957-61.

Moradi MT (2014). A novel, efficient, fast and inexpensive DNAextraction protocol from whole blood applicable for studying drug-DNA interaction. J Rep Pharm Sci, 3, 80-4.

Moradi MT, Hashtchian AR, Yari K (2013). Helicobacter pylori cagA-positive strains: gastric cancer susceptibility. Biharean Biologist, 7, 86-9.

Nicklin MJ, Weith A, Duff GW (1994). A physical map of the region encompassing the human interleukin-1 alpha, interleukin-1 beta, and interleukin-1 receptor antagonist genes. Genomics, 19, 382-4.

Parkhill JM, Hennig BJ, Chapple IL, et al (2000). Association of interleukin-1 gene polymorphisms with early-onset periodontitis. J Clin Periodontol, 27, 682-9.

Rad R, Dossumbekova A, Neu B, et al (2004). Cytokine gene polymorphisms influence mucosal cytokine expression, gastric inflammation, and host specific colonisation during Helicobacter pylori infection. Gut, 53, 1082-9.

Wen YY, Pan XF, Loh M, et al (2014). Association of the IL$1 \mathrm{~B}^{+3954} \mathrm{C} / \mathrm{T}$ polymorphism with the risk of gastric cancer in a population in Western China. Eur J Cancer Prev, 23, 35-42.

Yu H, Sun S, Liu F, et al (2014). Meta-analysis of associations between interleukin-17 Gene polymorphisms and risk of gastric cancer. Asian Pac J Cancer Prev, 15, 8709.

Zare A, Mahmoodi M, Mohammad K, et al (2013). Survival analysis of patients with gastric cancer undergoing surgery at the iran cancer institute: a method based on multi-state models. Asian Pac J Cancer Prev, 14, 6369-73.

Zeng ZR, Hu PJ, Hu S, et al (2003). Association of interleukin 1B gene polymorphism and gastric cancers in high and low prevalence regions in China. Gut, 52, 1684-9. 